Arch. Environ. Contam. Toxicol. 22, 219-227 (1992)

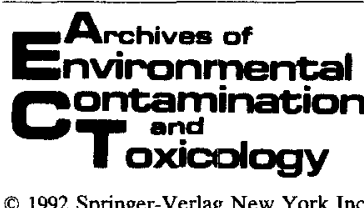

(C) 1992 Springer-Verlag New York Inc.

\title{
4-(4-Nitrobenzyl)pyridine Tests for Alkylating Agents Following Chemical Oxidative Activation
}

\author{
J. J. Thomas*, J. H. Kim**, and D. M. Mauro* \\ *Department of Biological Sciences, Florida Institute of Technology, Melbourne, Florida 32901, USA and **Environmental Chemistry \\ Program, Department of Environmental and Industrial Health, School of Public Health, The University of Michigan, \\ Ann Arbor, Michigan 48109, USA
}

\begin{abstract}
A chemical activation system (CAS) designed to mimic the mammalian mixed-function oxidase enzymes was found to activate target compounds to reactive electrophiles. Activated compounds were assayed by reaction with 4-(4nitrobenzyl)pyridine (NBP). A model nucleophile of 7-alkylguanine of nucleic acids, NBP produces a violet color following alkylation. Twenty compounds from several chemical classes were tested. The test generally gave positive and negative responses where expected. Two compounds, trichloroethylene and diethylnitrosamine, exhibited a linear Beer's law relationship in the concentration range tested. A high degree of linear correlation $(r>0.97)$ was obtained for these compounds. Other compounds showed varying degrees of linear correlation from high correlation $(r=0.94)$ to weak correlation $(r=0.44)$. The CAS-NBP assay results were compared to bacterial mutagenicity and animal carcinogenicity test results when information was available. A good correlation $(r=0.80)$ existed between direct alkylating activity and direct mutagenicity. Similar correlations existed between NBP alkylation following activation and mutagenicity following microsomal activation $(r=0.73)$. Also, different correlations were observed between carcinogenicity and NBP alkylation following activation $(r=0.69)$ and without activation $(r=0.38)$.
\end{abstract}

It is widely accepted that mutagenicity and, in many cases, carcinogenicity are the result of the binding of active genotoxic compounds or their reactive metabolites to specific, sensitive sites on informational molecules (Bartsch et al. 1983). The genotoxins are generally regarded to be electrophilic, e.g., carbonium ions, epoxides, and other alkylating species. A link has been established between the electrophilic attack on informational macromolecules and induction of cancer. Further, the critical role of metabolic enzymes in the production of reactive electrophiles has been revealed.

Long-term bioassay with small mammals has been the traditional test protocol to determine chemical genotoxins (Peto et al. 1984; Tennant et al. 1987). In response to prohibitively high costs and excessive time requirements, sev- eral in vitro test systems have been developed. Most utilize lower organisms (bacteria, viruses) or cells in culture which are simple enough so that perturbation in the organism's DNA can be readily observed. Metabolic activation is usually accomplished with a homogenate of rat liver tissue. Several chemical reagents which model biochemical nucleophiles and produce a detectable endpoint upon electrophilic attack have been studied. Although increasingly divergent from in vivo conditions, chemical systems afford considerable savings in time and money, as well as providing for detailed study of the very basic reactions of genotoxicity.

Several alkylating agents were assayed using NBP as an analytical agent for estimation of their alkylating activities; it has been used to assay herbicides such as dimethyl tetrachloroterephthalate (Schuldt et al. 1961), organophosphate pesticides (Getz and Watts 1964; Ragab 1967); nitrogen mustards (Friedman and Boger 1961); haloalkanes and alkenes (Sawicki et al. 1963); azirdines (Bardos et al. 1965) nitrosourea compounds (Yano and Isobe 1979); epoxides (Hemminki et al. 1980; Ehrenberg and Hussain 1981; Voogd et al. 1981; Hemminki and Hesso 1984).

An understanding of the biochemistry of genotoxins has led to the preliminary development of a modified NBP test system (Archer and Eng 1981). However, this test system depended on the use of gaseous oxygen which made it difficult and time consuming to employ. A modified chemical activation system (CAS) employing hydrogen peroxide in place of oxygen and designed to mimic the mammalian mixed oxidase enzymes, was developed and tested in this laboratory (Kim and Thomas 1991). A mixture of hydrogen peroxide, ascorbic acid, ferrous ion, EDTA, and hydrazine in phosphate buffer activated target compounds to reactive electrophiles. By applying the chemical activation system to alkylating agents, genetic risks may be quickly and reliably estimated. Also, the use of a chemical approach by the chemical activation system prove to be helpful in detecting and elucidating the structure-activity relationships of carcinogenic and mutagenic alkylating agents in environmental samples without employing complex and expensive biological systems.

A chemical activation system-assay system consisting of a 
mixture of hydrogen peroxide, ascorbic acid, ferrous ion, EDTA, and hydrazine in monophosphate buffer, is presented to mimic the mammalian mono-oxygenase system via hydroxyl radical production. NBP provides the model nucleophile, producing a colored product upon electrophilic attack. Results obtained with several rest compounds as well as details of mechanisms are presented.

\section{Materials and Methods}

\section{Chemicals}

All solvents and trichloroethylene used were nanograde from Mallinckrodt, St. Louis, MO. $p, p$-1,1-Dichloro-2,2-bis ( $p$ chlorophenyl)ethane (DDD) $(99+\%), p, p-1,1$-dichloro-2,2-bis( $p$-chlorophenyl)ethylene (DDE) (99\%), p,p-1,1-dichloro-2,2bis(p-chlorophenyl)-2-chloroethylene (DDMU) (98\%), p,p-1,1dichloro-2,2-bis( $p$-chlorophenyl)-ethylene (DDNU) (98\%) and $p, p$-1,1-dichloro-2,2-bis(chlorophenyl)ethane (DDT) $(99+\%)$, and 4-(4-Nitrobenzyl)pyridine (98\%), 1,2-dibromoethylene (98\%), 1,1Dimethylhydrazine $(99+\%)$, 1,2-dimethylhydrazine $(97 \%)$ were obtained from Aldrich Chemical Co., Milwaukee, WI., acrylamide $(99+\%)$ and acrylonitrile (practical) from Eastman Chemical Co., diethylnitrosamine (99\%) from Sigma, St. Louis, MO.. 2,4hexadienal (96\%) and 1,1,2,2-tetrachloroethene from EPA (Research Triangle Park), acrylic acid (97\%) fumaric acid $(99+\%)$ and allyl alcohol (97\%) from Matheson, Coleman and Bell, Norwood, $\mathrm{OH}$. Other agents and substrates were analytical grade or were of highest purity, and generally were used without further purification.

\section{Procedures}

The test procedure was carried out in the absence (A) or presence (B) of activation system.

(A) Detection of alkylating agents in the absence of activation: To a reaction tube was added $3.0 \mathrm{~mL}$ of $0.2 \mathrm{M}$ sodium acetate-acetic buffer ( $\mathrm{pH} 4.0$ ), the test compound in $2.0 \mathrm{~mL}$ of acetone, and $1.0 \mathrm{~mL}$ of $5 \%(\mathrm{w} / \mathrm{w}) 4-\mathrm{NBP}$ in acetone (solvent). Sufficient water was added to produce a total volume of $7.0 \mathrm{~mL}$. Blank samples were made in the same manner without adding a test compound. The reaction flask was sealed with Teflon tape and placed in a boiling water bath. After $20 \mathrm{~min}$, the solution was chilled in ice and $0.6 \mathrm{~mL}$ of ethyl acetate/acetone $(5: 2, \mathrm{v} / \mathrm{v})$ added, followed by $1.0 \mathrm{~mL}$ of $5 \mathrm{~N}$ sodium hydroxide. After mixing in a vortex mixer for about $30 \mathrm{sec}$, the organic phase was separated in a separatory funnel, removed, and the absorbance read at $540 \mathrm{~nm}$ with UV-spectrometer. All absorbance readings were carried out exactly $1.75 \mathrm{~min}$ after the addition of $\mathrm{NaOH}$.

(B) Detection of alkylating agents following activation: To $3.0 \mathrm{~mL}$ of $0.1 \mathrm{M}$ potassium phosphate buffer (monobasic, $\mathrm{pH} 4.5$ ) containing $10 \mathrm{mM}$ EDTA was added $0.1 \mathrm{~mL}$ of $0.15 \mathrm{M}$ ferrous sulfate and 0.1 $\mathrm{mL}$ of $1,0 \mathrm{M}$ ascorbic acid. The test compound in $2.0 \mathrm{~mL}$ of acetone (solvent) and $1.0 \mathrm{~mL}$ of $0.5 \mathrm{M}$ hydrazine solution was then added. Finally, 30\% hydrogen peroxide was added to make $0.8 \mathrm{M}(1 \mathrm{~mL})$. Blank samples were made in the same manner without adding a parent compound. The reaction tube was sealed with Teflon tape and its content mixed by inverting twice. After $20 \mathrm{~min}$, the reaction mixture was incubated in a shaker bath at $37^{\circ} \mathrm{C}$ for $20 \mathrm{~min}$. The solution was chilled in ice and $0.6 \mathrm{~mL}$ of ethyl acetate/acetone $(5: 2)$ added, followed by $1.0 \mathrm{~mL}$ of $5 \mathrm{~N}$ sodium hydroxide. After mixing in a vortex mixer for about $30 \mathrm{sec}$, the organic phase was separated in a separatory funnel, removed, and the absorbance read at $540 \mathrm{~nm}$ with a UV-spectrometer (Beckman). All absorbance readings were carried out exactly 1.75 min after the addition of $\mathrm{NaOH}$.

\section{Results}

1. Halogenated Hydrocarbons: Ethylene Dichloride, Trichloroethylene, 1,1,2,2-Tetrachloroethene, 1,2-Dibromoethylene

Ethylene dichloride (DCE) is a common industrial and laboratory compound. Ethylene dichloride (1,2-dichloroethene, DCE) has been shown to be both direct acting and oxidatively activated in the $\mathrm{H}_{2} \mathrm{O}_{2}$-ascorbic-hydrazine system (Table 1). Although an apparently linear increase in absorbance with concentration, following chemical activation, was shown, the precision was poor $\left(r^{2}=0.47\right)$ (Figure 1). The reason for the scattered data was not known. The mechanism for direct alkylation of NBP (Y: nucleophile) by DCE was most likely a general $\mathrm{SN}_{2}$ alkylation reaction (Eq. 1).

$$
\mathrm{ClCH}_{2} \mathrm{CH}_{2} \mathrm{Cl}+\mathrm{NBP}(\mathrm{Y}) \rightarrow \mathrm{ClCH}_{2} \mathrm{CH}_{2} \mathrm{NBP}^{+}+\mathrm{Cl}^{-}
$$

Chemical activation of DCE was most likely more complex (Eq. 2).

$$
\begin{array}{cl}
\mathrm{OH}^{*} \\
\mathrm{ClCH}_{2} \mathrm{CH}_{2} \mathrm{Cl} \rightarrow & \mathrm{ClCH}_{2} \dot{\mathrm{CHCl}}+\mathrm{H}_{2} \mathrm{O} \\
\downarrow & \mathrm{OH}^{*} \\
\mathrm{ClCH}_{2} \mathrm{CH}-\mathrm{Cl} & \rightarrow \mathrm{OH}_{2}-\mathrm{CHCl}+\mathrm{HCl}
\end{array}
$$

Results demonstrated that oxidative activation increased the alkylation rate of DCE over direct acting mechanisms (Table 1).

Alkylation of NBP by DCE following chemical activation was also less (1.6 times) than by TCE, 5.8 a.u./mmol. In the bacterial assay, conjugation to glutathione was the activation mechanism which differed from the in vitro mechanism (Rannug et al. 1978, 1979) (Eq. 3).

$$
\begin{array}{r}
\mathrm{ClCH}_{2} \mathrm{CH}_{2} \mathrm{Cl}+\mathrm{GSH} \rightarrow \mathrm{ClCH}_{2} \mathrm{CH}_{2} \mathrm{SG}+\underset{\text { internal }}{\mathrm{HCl}} \\
\downarrow \text { nucleophilic } \\
\text { substitution } \\
\qquad \mathrm{GH}^{\mathrm{CH}_{2}-\mathrm{CH}_{2}+\mathrm{Cl}^{-}}
\end{array}
$$

Trichloroethylene (TCE) was not a direct alkylating agent to NBP in this study. It was activated to an alkylating agent by the chemical activation system (CAS). Alkylation of NBP following chemical activation was observed for the concentration range 50-200 $\mu$ moles TCE. A correlation coefficient (r) of 0.998 and an $r^{2}$ of 0.996 indicated close confirmity to Beer's law (Figure 2). Distinct peaks with absorbance maxima at $540 \mathrm{~nm}$ were observed. The high molar absorbance of the TCE oxirane $(9.2$ a.u. $/ \mathrm{mmol})$ and the high precision $\left(\mathrm{r}^{2}=\right.$ 0.996 ) indicated a stable oxidation product.

Activation of TCE by the chemical activation system was considered to involve the addition of an atom of oxygen to 
Table 1. Alkylation of 4-(4-nitrobenzyl)pyridine with and without chemical activation system (CAS)

\begin{tabular}{|c|c|c|c|c|}
\hline Compound & $\begin{array}{l}\text { Abs } / \mathrm{mM} \\
\text { without CAS }\end{array}$ & $\begin{array}{l}\mathrm{Abs} / \mathrm{mM} \\
\text { with CAS } \\
\mathrm{x} \pm \mathrm{s}_{\mathrm{m}}\end{array}$ & Regression & $\mathbf{R}$ \\
\hline Ethylene dichloride & 0.41 & $5.8 \pm 0.7$ & $Y=5.5 x+0.04$ & 0.47 \\
\hline Trichloroethylene & 0.0 & $9.2 \pm 0.07$ & $Y=9.1 x+0.01$ & 0.998 \\
\hline Tetrachloroethylene & 0.0 & $0.0^{\mathrm{a}}$ & $Y=2.3 x-0.11$ & 0.84 \\
\hline 1,2-Dibromoethylene & 6.6 & $8.5 \pm 1.4$ & $Y=6.1 x+0.17$ & 0.79 \\
\hline DDT & 0.0 & 0.0 & - & - \\
\hline DDD & 0.0 & 0.0 & - & - \\
\hline DDE & 0.0 & $4.4 \pm 2.0$ & $Y=5.3 x+0.00$ & 0.94 \\
\hline DDMU & 0.0 & 0.0 & - & - \\
\hline DDNU & 0.0 & 0.0 & - & - \\
\hline Allyl alcohol & 0.0 & $10.6 \pm 5.4$ & $Y=2.4 x+0.58$ & 0.50 \\
\hline Acrylamide & 50 & $1.9 \pm 0.8$ & $Y=0.14 x+0.2$ & 0.44 \\
\hline Acrylic acid & 50 & $6.6 \pm 0.6$ & $Y=5.4 x+0.11$ & 0.80 \\
\hline Acrylonitrile & 19 & $8.6 \pm 0.9$ & $Y=12.6 x-0.34$ & 0.93 \\
\hline Diethylnitrosamine & 0.0 & $0.9 \pm 0.3$ & $Y=1.6 x-0.09$ & 0.999 \\
\hline Fumaric acid & b & $6.6 \pm 1.9$ & $Y=15.4 x-0.4$ & 0.74 \\
\hline 2-Furoic acid & 0.0 & $8.5 \pm 1.9$ & $Y=4.0 x+0.32$ & 0.58 \\
\hline 2,4-Hexadienal & 18 & $2.6 \pm 0.4$ & $Y=3.5 x-0.03$ & 0.92 \\
\hline Caffeine & 0.0 & 0.0 & - & - \\
\hline 1-Methylhydrazine & 0.0 & $0.03 \pm 0.02^{\mathrm{a}}$ & - & - \\
\hline 1,1-Dimethylhydrazine & 0.0 & $0.1 \pm 0.05^{\mathrm{a}}$ & - & - \\
\hline
\end{tabular}

${ }^{a}$ Indicates a questionable result. ${ }^{b}$ an intense blue color developed in an aqueous phase, but the absorbance was not determined

the olefinic bond with the consequent production of trichloroethylene oxide and then a 2-hydroxyalkylated product resulted from nucleophilic attack (Eq. 4).<smiles>[Y]C(C(=O)O)C([3H])([O-])C([3H])(Cl)C([Y])(Cl)Cl</smiles>

Indeed, this mechanism has been proposed as the activation pathway involved in microsomal oxidation in vivo (Bartsch et al. 1983).

1,1,2,2-Tetrachloroethylene (TTCE) was non-alkylating with or without chemical activation (Table 1). One positive result was obtained with the CAS at high concentration, however no indication of a Beer's Law relationship existed in the concentration range tested (Figure 3). Therefore, a positive response could not be reported, and the result was consequently labeled questionable. An identical activation mechanism can be postulated for TTCE as for TCE. However, some factor, possible steric hindrance, has prevented the formation of the oxirane in in vitro tests.

Alkylation of NBP by 1,2-dibromoethylene (DBE) has been demonstrated with and without activation (Table 1). The response following activation was linear, however the correlation was low $\left(\mathrm{r}^{2}=0.79\right)$ (Figure 4). However, an increase in alkylating activity following activation was shown. Direct alkylating activity was not anticipated for
DBE. Activation of DBE occurs by epoxidation of the double bond (Eq. 5).<smiles>O[14CH2]C(Br)=C(Br)Br</smiles>

\section{DDT and Metabolites: $D D D, D D E$, $D D M U, D D N U$}

The activity of DDT and four of its metabolites in the $\mathrm{H}_{2} \mathrm{O}_{2}$ ascorbic-hydrazine activation system was investigated. The results are given in Table 1 . None of the five compounds showed direct alkylating activity. Only DDE exhibited alkylating activity following activation, but its response was weak and inconsistent (Figure 5). Three reasons for the lack of positive responses were possible. One, DDT and its metabolites are practically insoluble in water. It was therefore, necessary to examine very small quantities of each compound in the essentially aqueous activation system. Two, activation of DDT and derivatives appears to be slow under the conditions studied (Planche et al. 1979). The chemical activation technique is rapid, and it is possible that more time is necessary for significant quantities of active intermediates to form. Lastly, as indicated by DDNU-oxide, oxiranes asymetrically substituted with two $p$-chlorophenyl groups may show low chemical reactivity, i.e., low electrophilic activity. Alkylation of NBP has been demonstrated with DDD and DDNU-oxide. Positive results with DDD or DDNU could not be demonstrated with the chemical activation-NBP system (Table 1). 
Fig. 1. Ethylene Dichloride

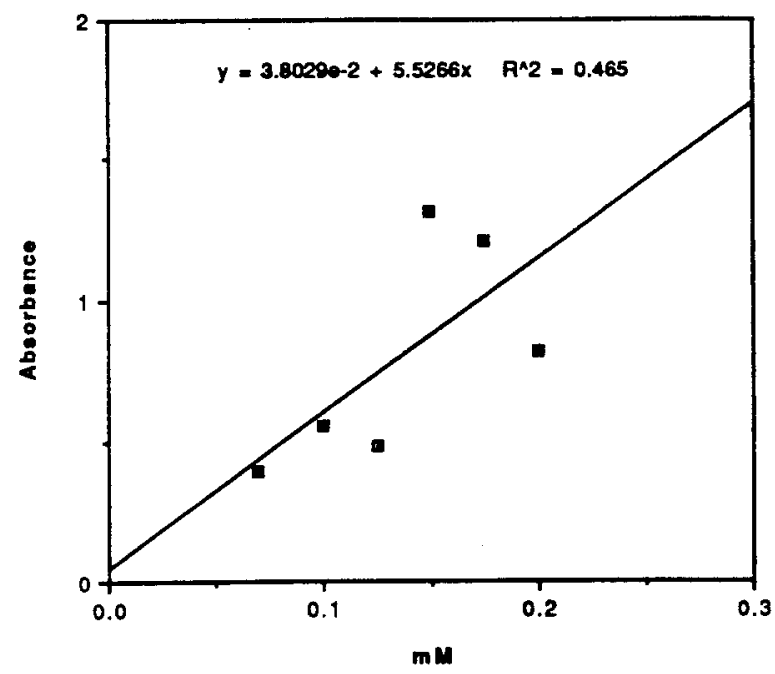

Fig. 3. Tetrachloroethylene

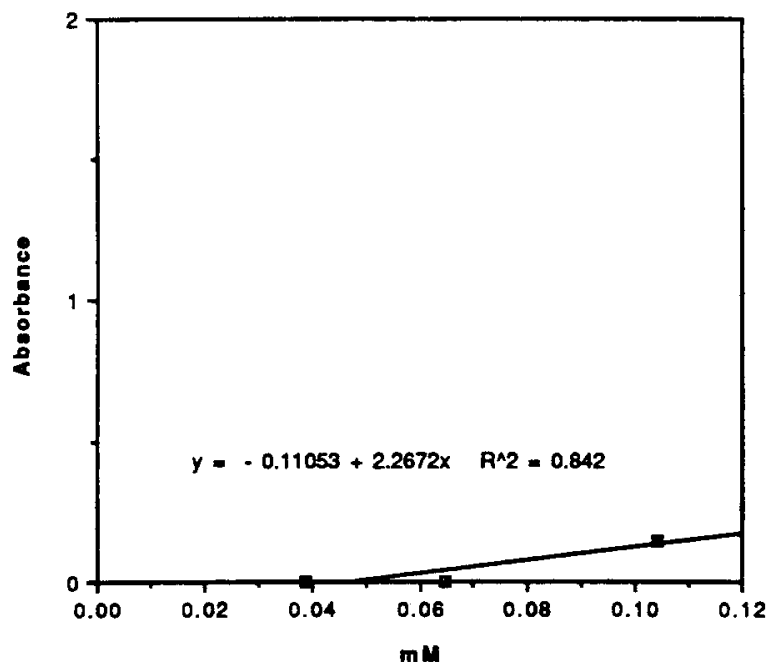

Fig. 5. DDE

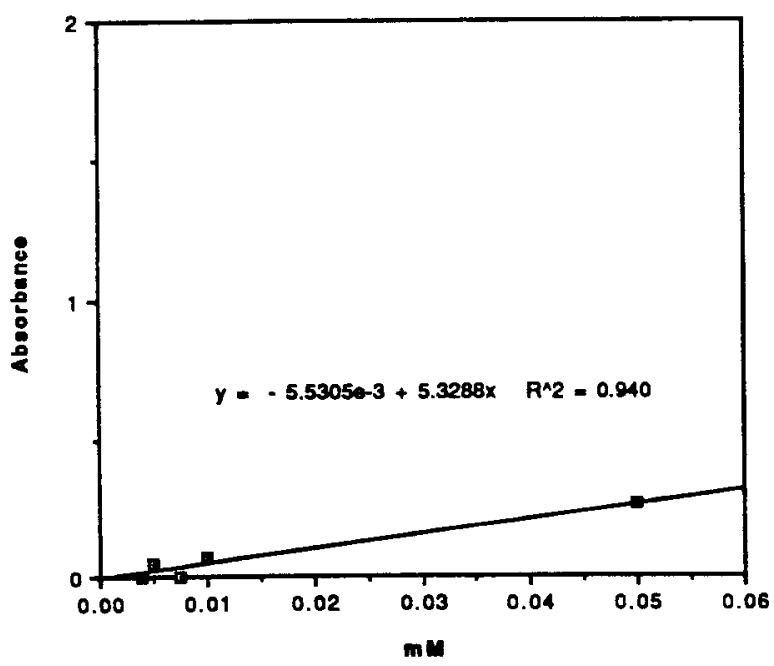

Fig. 2. Trichloroethylene

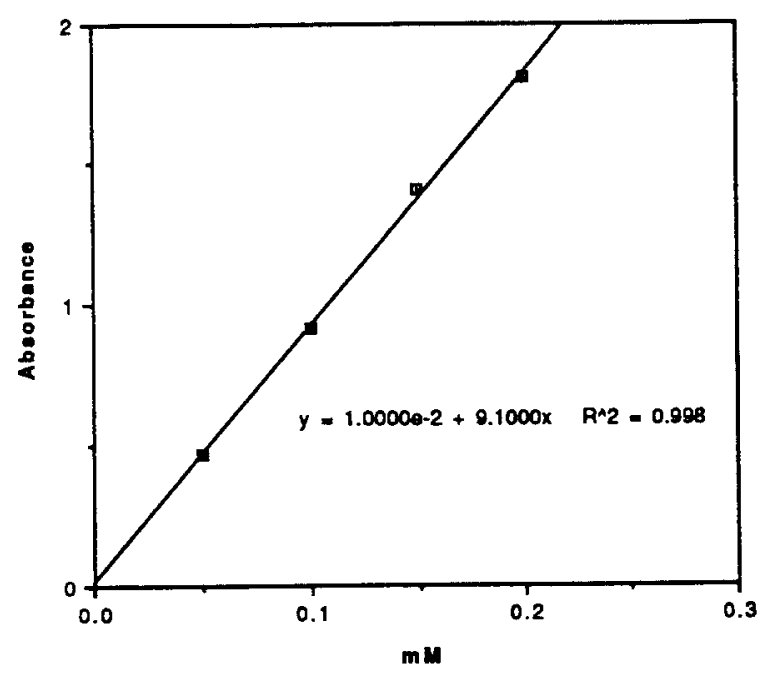

Fig. 4. 1,2-Dibromoethylene

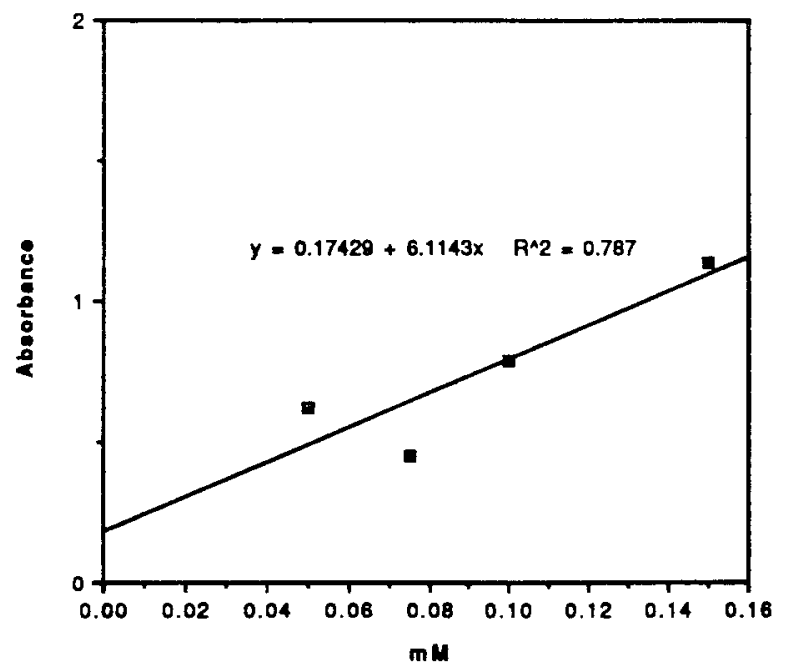

Fig. 6. Allyl Alcohol

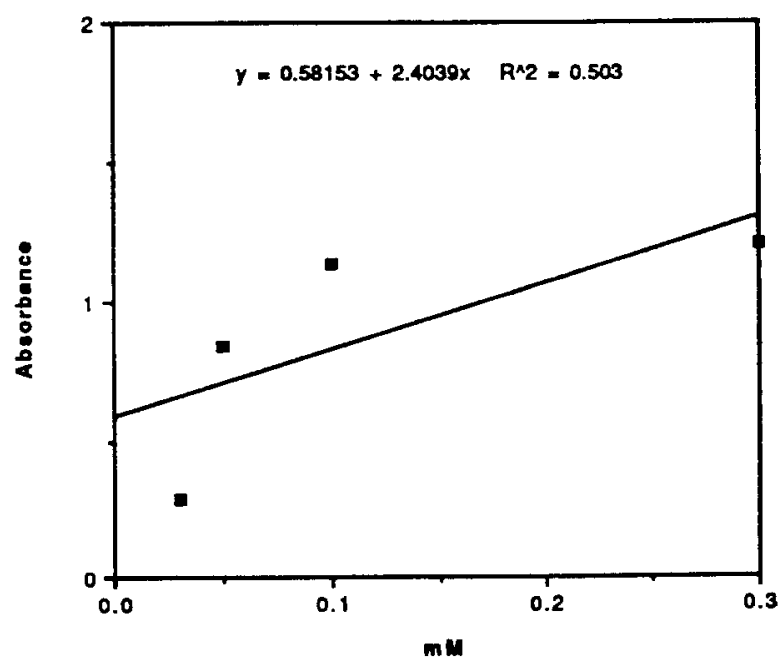


Fig. 7. Acrylamide

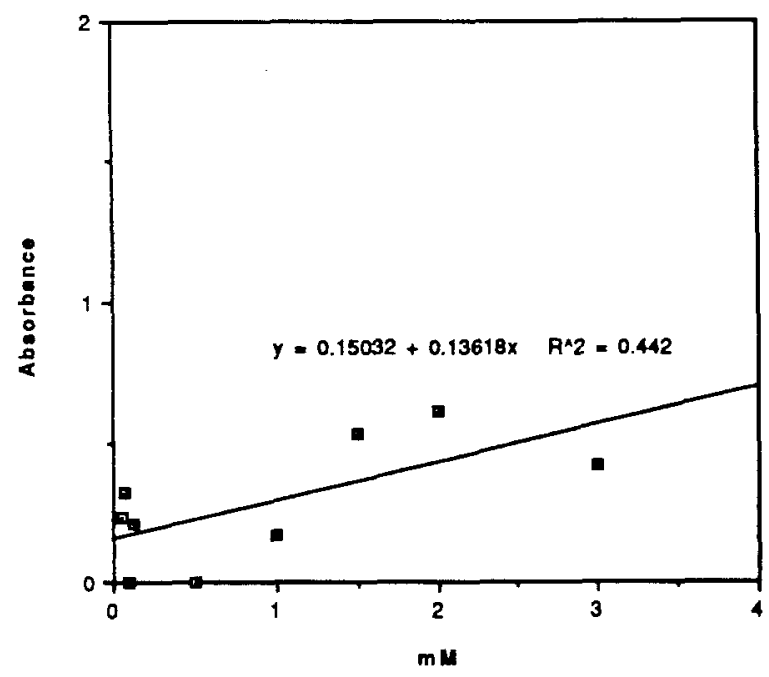

Fig. 9. Acrylonitrile

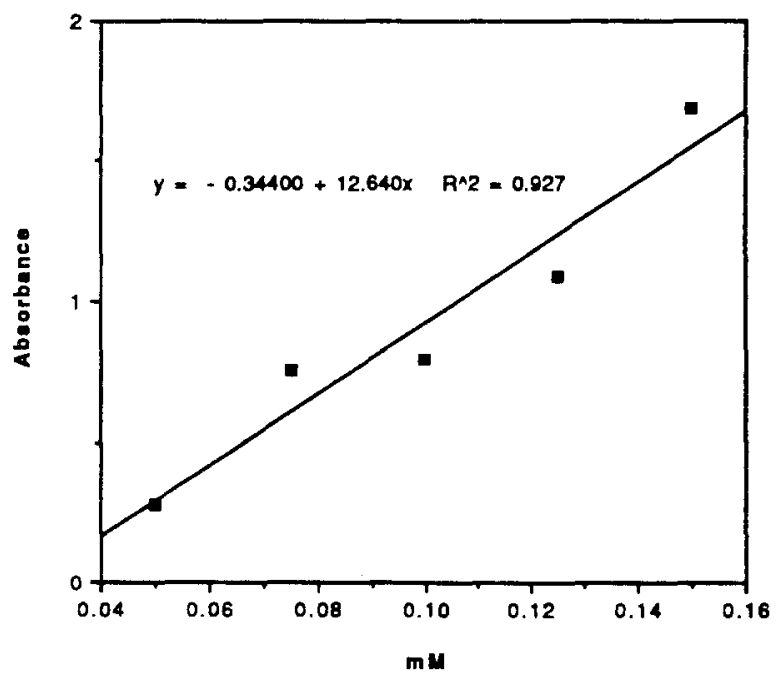

Fig. 11. Fumaric Acid

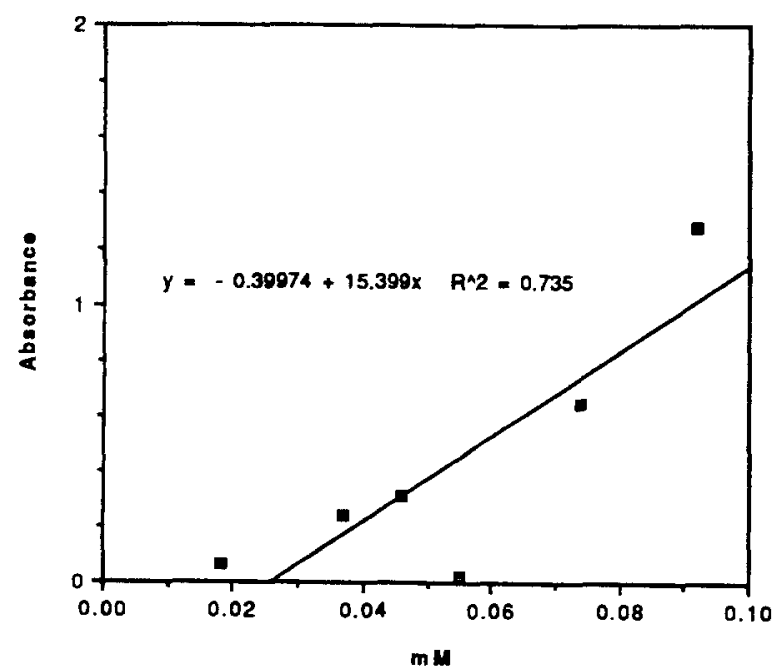

Fig. 8. Acrylic Acid

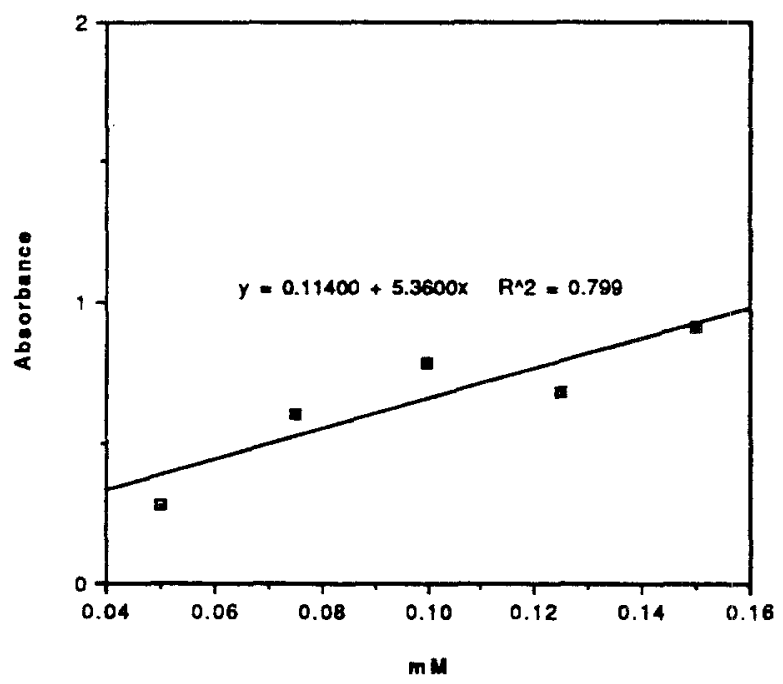

Fig. 10. Diethylnitrosamine

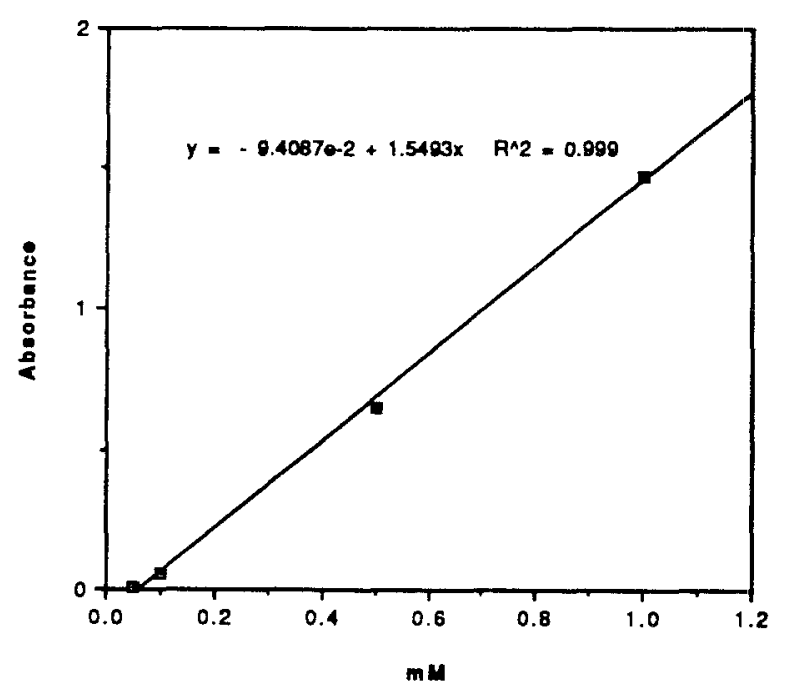

Fig. 12. 2-Furoic acid

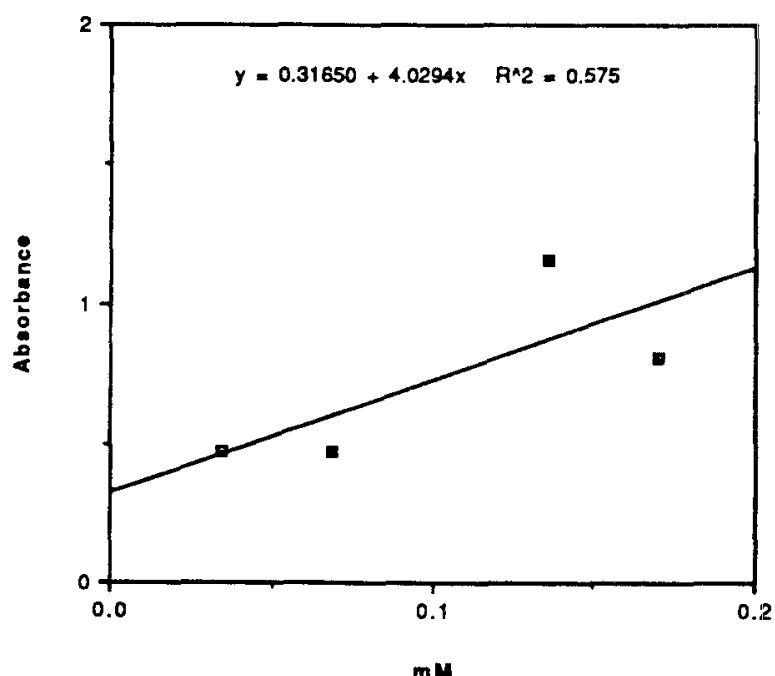


Fig. 13. 2,4-Hexadienal

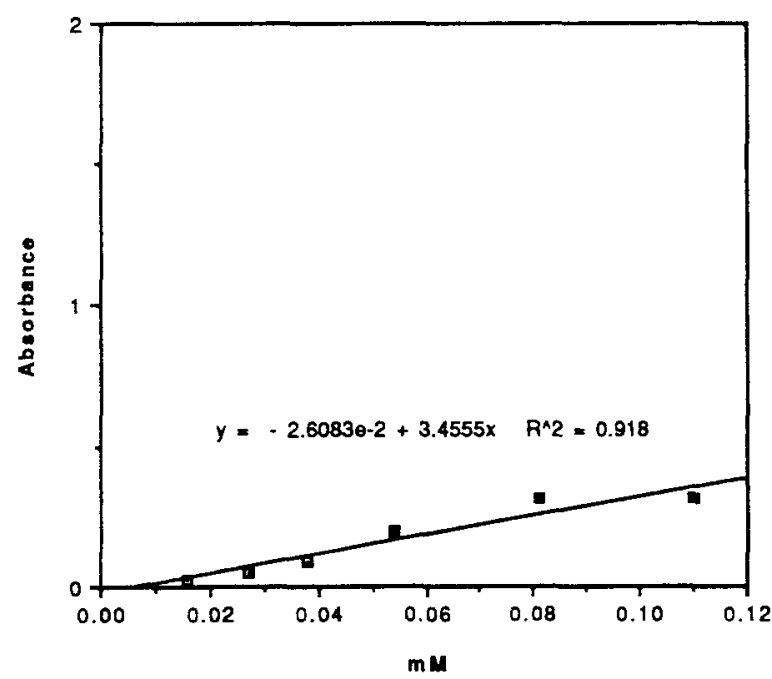

Figs. 1-13. Linear concentration-absorbance relationship of alkylating agents

\section{Allyl Alcohol, Acrylamide, Acrylic Acid, Acrylonitrile}

These classes of compounds contain an olefinic structure which has been commonly associated with metabolic epoxidation. Because of these concerns, four compounds from this class were examined in the CAS-NBP assay system. Allyl alcohol was not a direct alkylating agent (Table 1). It did however alkylate NBP following activation. The response of the alkylating activity was not linear $(r=0.50)$ over the entire concentration range ( $30-300 \mu$ moles) (Figure 6). A rapid increase in absorbance occurred up to approximately $100 \mu$ moles. In this range absorbance per mole averaged 13. At greater than $100 \mu$ moles, absorbance decreased, averaging 3.7 in the 100 to $300 \mu \mathrm{mol}$ range. Formation of a reactive epoxide was the most likely activation mechanism. Results with the chemical activation system clearly indicated that, indeed, allyl alcohol is not a direct alkylating agent; however, it is readily converted to an active electrophile in this system. Alkylation of NBP was investigated with three common acrylic compounds (acrylamide, acrylic acid, and acrylonitrile). Each compound exhibited strong electrophilic activity in the absence of a CAS, and much reduced electrophilic activity following chemical activation (Table 1). Acrylamide exhibited no linear relationship between concentration and absorbance with chemical activation in the concentration range of 50-3,000 $\mu$ moles (Figure 7). A general increase in absorbance was observed at higher concentrations, however, no linear trend was apparent in this range. The results suggested that no activation was in fact occurring. Deactivation appeared the primary mechanism, with the greater absorbances at higher concentrations the result of overwhelming the deactivation reactions. A correlation coefficient of 0.88 was obtained for alkylation of NBP by acrylic acid following activation (Figure 8). Some mechanism, not operating with acrylamide appeared to be active with acrylic acid. Since this may have been the expected epoxidation of the double bond, competing activation and deactivation reactions appeared responsible for the rela- tively low precision. In the absence of chemical activation, resonance forms of acrylic acid were the likely alkylating species as shown in Eq. 6 (Roberts and Caserio 1964).

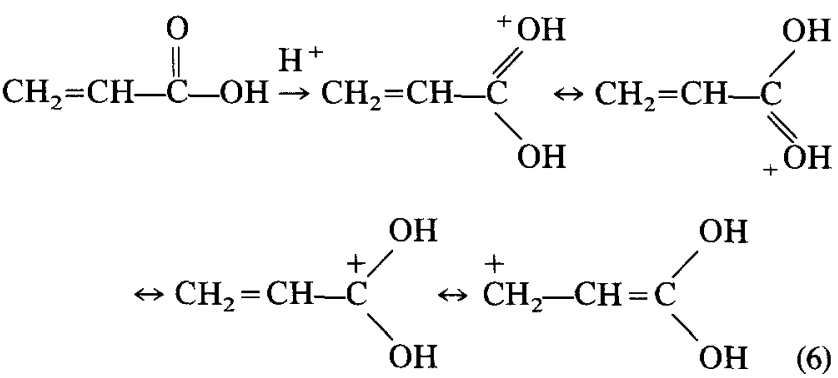

A similar mechanism can be proposed for acrylamide (Eq. 7).

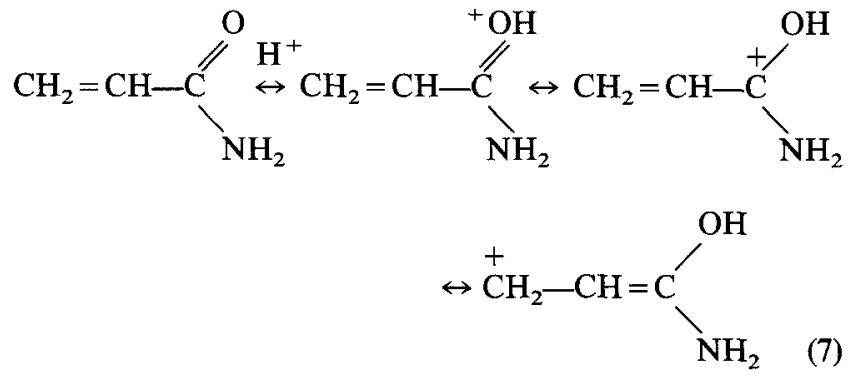

Acrylonitrile exhibited direct and activated alkylating activity to NBP (Table 1). The direct alkylating potency was somewhat less than that of acrylic or acryamide. Also, the proposed alkylating species must be derived by a somewhat different mechanism than that of acrylic acid or acrylamide, because acrylonitrile has no carbonyl oxygen. The following resonance forms (Eq. 8) are suggested based on the large dipole moment (4.0 D) of the nitrile functional groups (Roberts and Caserio 1964).

$$
\begin{aligned}
\mathrm{CH}_{2}=\mathrm{CH}-\mathrm{C} \equiv \mathrm{N} \leftrightarrow \mathrm{CH}_{2}= & \mathrm{CH}-\stackrel{+}{\mathrm{C}}=\mathrm{N}^{-} \\
& \leftrightarrow{ }^{+} \mathrm{CH}_{2}-\mathrm{CH}=\mathrm{C}=\mathrm{N}^{-}
\end{aligned}
$$


Apparently, the production of acrylonitrile resonance forms is less favored than those of acrylic acid or acrylamide, as implied by the lower absorbance per mmole per compound in the direct NBP test.

Absorbance following activation was less for all tested acrylic compounds than that without activation. However, for acrylonitrile a strong concentration-absorbance correlation ( $\mathrm{r}=0.93, \mathrm{r}^{2}=0.86$ ) was evident (Figure 9). Bardos et al. (1965) reported that the reaction of NBP with the alkylating agents tested was $\mathrm{SN}_{2}$, as indicated by a rate dependence on both the alkylating agent concentration and the concentration of NBP. Assuming the functional groups as a major factor in activated acrylate reactivity in terms of structure-activity relationships, then the three acrylic compounds can be ranked from highest to least reactivity: acrylonitrile $>$ acrylic acid $>$ acrylamide. Indeed, the absorbance per mmole values for these compounds in the CAS-NBP assay can be ranked: acrylonitrile, $8.6>$ acrylic acid, $6.6>$ acrylamide, 1.9. Activation to epoxides is, therefore, indicated at least for acrylonitrile and acrylic acid. Interestingly, the reverse was observed in the absence of activation.

\section{Diethylnitrosamine (DEN)}

DEN was reported to alkylate NBP following activation in the Udenfriend system (Archer and Eng 1981). DEN was not alkylating without activation (Table 1). Following activation it was found to be a somewhat weak alkylating agent. A linear concentration-absorbance relationship was evident with a high degree of correlation $\left(r=0.999, r^{2}=0.998\right)$ (Fig. 10). Activation of DEN is initiated in vitro by $\alpha$-hydroxylation. Several steps eventually lead to production of a carbonium ion (Eq. 9).

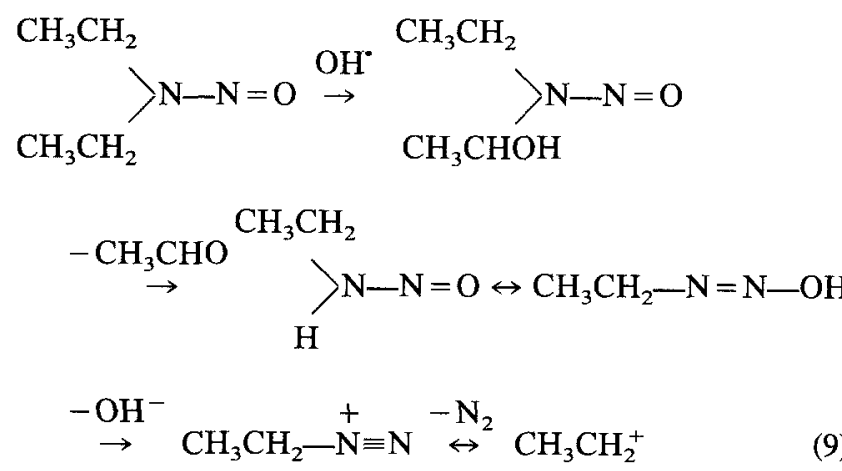

DEN has been known to covalently bond to DNA at several sites such as $\mathrm{N}$ or $\mathrm{O}$ atom of guanine base (Farber 1982).

\section{Fumaric Acid, 2-Furoic acid,} 2,4-Hexadienal, Caffeine

Results indicated that fumaric acid was both a direct and an indirect alkylating compound. In the test without activation, fumaric produced an intensely blue chromophore with NBP that could not be extracted into ethyl acetate. This indicated a water-soluble alkylated product. This was unique amongst the compounds tested. All other direct alkylating agents tested formed an ethyl acetate-soluble chromophore. Reso- nance forms of fumaric acid may have been responsible for the observed activity (Eq. 10).<smiles>CO/C(O)=C/[CH+]C(=O)O</smiles>

Absorbance values were not obtained for quantitative analysis. Fumaric acid was also alkylating following chemical activation. A poor linear relationship was obtained in the concentration range tested (20-100 $\mu$ moles) (Figure 11). Solubility of activated fumaric acid-NBP chromophore in ethylacetate indicated a different alkylating intermediate, produced possibly by epoxidation of the double bond (Eq. 11).<smiles>O=C(O)C=CC(=O)O</smiles>

Alkylation of NBP by 2-furoic acid did not occur in the absence of chemical activation, but did occur following activation. A poor overall linear relationship was found ( $r=$ $0.58, \mathrm{r}^{2}=0.34$ ) (Figure 12). Alkylation of NBP increases steadily until approximately 0.15 mmole of 2-furoic acid had been added, then decreased. Alkylation of NBP by 2,4hexadienal (HDA) occurred with and without chemical activation. HDA was a strong direct alkylating agent with an absorbance per mmole of 18 . The reactive electrophile most likely was caused by delocalization of the electrons (Eq. 12). Activation of HDA was expected to<smiles>CC=CC=C=C(O)C(=O)O</smiles>

occur through epoxidation of one or both of the olefinic bonds. However, absorbance following activation was greatly reduced from non-activated tests. It was impossible to determine if alkylation in the CAS-NBP system was caused by epoxide formation or residual resonance forms. A weak linear relationship was apparent (Figure 13).

\section{1,1-Dimethylhydrazine, 1,2-Dimethylhydrazine, 1-Methylhydrazine}

Three hydrazine derivatives were assayed with the CASNBP assay. None were direct alkylating compounds. 1,1Dimethylhydrazine (UDMH) and 1-Methylhydrazine (MMH) were weakly active following activation. The proposed mechanism by which alkylhydrazines are activated is represented by UDMH (Eq. 13) (Hathway 1984). 
Table 2. Correlation of CAS-NBPw system results with reported bacterial mutagenicity and carcinogenicity studies

\begin{tabular}{|c|c|c|c|c|c|}
\hline \multirow{3}{*}{$\frac{\text { Compound }}{\text { Ethylene dichloride }}$} & \multicolumn{2}{|c|}{ NBP assay } & \multirow{2}{*}{\multicolumn{2}{|c|}{$\begin{array}{l}\text { Mutagenicity with/without } \\
\text { microsomal activation }\end{array}$}} & \multirow{3}{*}{$\frac{\text { Carcinogenicity }}{t^{c}}$} \\
\hline & \multirow{2}{*}{$\begin{array}{l}\text { With } \\
+\end{array}$} & \multirow{2}{*}{$\frac{\text { Without }}{+}$} & & & \\
\hline & & & $++^{a}$ & $t^{a, b}$ & \\
\hline Trichloroethylene & + & - & $+^{d}$ & $-d$ & $+^{e}$ \\
\hline Tetrachloroethylene & - & - & $-d$ & $-d$ & $-{ }^{f}$ \\
\hline 1,2-Dibromoethylene & + & + & ND & ND & ND \\
\hline DDT & - & - & $-{ }^{\mathrm{h}}$ & $-\mathrm{g}, \mathrm{h}$ & $+\mathrm{g}, \mathrm{h}$ \\
\hline DDD & - & - & $+^{\mathrm{b}}$ & $-\mathrm{g}, \mathrm{h}$ & $+\mathrm{g}, \mathrm{h}$ \\
\hline DDE & + & - & $+\mathrm{g}$ & $\ldots$ g,h & $+\mathrm{g}, \mathrm{h}$ \\
\hline DDMU & - & - & $-\mathbf{h}$ & $-\mathrm{g}, \mathrm{h}$ & ND \\
\hline DDNU & - & - & $-{ }^{h}$ & $-\mathrm{g}, \mathrm{h}$ & ND \\
\hline Allyl alcohol & + & - & $-i$ & $-i$ & ND \\
\hline Acrylamide & + & + & ND & ND & $+t^{j}$ \\
\hline Acrylic acid & + & + & $\mathrm{ND}$ & ND & ND \\
\hline Acrylonitrile & + & + & $+^{\mathrm{k}}$ & $-{ }^{k}$ & -1 \\
\hline Diethylnitrosamine & + & - & $+^{\mathrm{m}, \mathrm{n}, \mathrm{o}}$ & $-\mathrm{m}, \mathrm{n}, \mathrm{o}$ & $+^{o, p}$ \\
\hline Fumaric acid & + & + & ND & ND & ND \\
\hline 2-Furoic acid & + & - & $-q$ & -9 & $-r$ \\
\hline 2,4-Hexadienal & + & + & ND & ND & ND \\
\hline Caffeine & - & - & $-m$ & $-\mathrm{m}$ & $-\mathrm{m}$ \\
\hline 1-Methylhydrazine & + & - & $-s$ & $t^{s}$ & $+{ }^{t}$ \\
\hline 1,1-Dimethylhydrazine & + & - & $+{ }^{u}$ & $+u$ & $+{ }^{v}$ \\
\hline
\end{tabular}

+ positive response; - negative response; ND no reported results

${ }^{\mathrm{a}}$ Rannug et al. $1979 ;{ }^{\mathrm{b}} \mathrm{Hemminki}$ et al. $1980 ;{ }^{\mathrm{C}} \mathrm{Chu}$ and Milman 1981; ${ }^{\mathrm{d} B a r t c h}$ et al. $1979 ;{ }^{\circ} \mathrm{Crebelli}$ and Carere 1989; ${ }^{\mathrm{f}} \mathrm{Manson} 1980 ;{ }^{\mathrm{g}} \mathrm{Williams}$

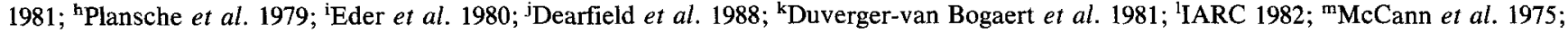
" Prival et al. 1979; ${ }^{\circ}$ Philipson and Ioannides 1984; ${ }^{\mathrm{P}} \mathrm{Habs}$ and Schmahl 1981; ${ }^{\mathrm{G}}$ Soska et al. 1981; ${ }^{\mathrm{r}}$ Aaron et al. 1989; ${ }^{\mathrm{s}} \mathrm{von}$ Wright and Tikkanen 1980; 'Hawks et al. 1974; "Bruce and Heddle 1979; ${ }^{\mathrm{v} H e d d l e}$ et al. 1983.

${ }^{\text {w }}$ Chemical Activation System-4-(4-nitrobenzyl)pyridine

Table 3. Correlation coefficients ( $r$ ) of CAS-NBPa system results with reported bacterial mutagenicity and carcinogenicity studies

\begin{tabular}{lll}
\hline & NBP assay & \\
\cline { 2 - 3 } & With & Without \\
& CAS & CAS \\
\hline Mutagenicity & & \\
Without microsomal activation & 0.60 & 0.80 \\
$\quad$ With microsomal activation & 0.73 & 0.67 \\
Carcinogenicity & 0.69 & 0.38 \\
\hline
\end{tabular}

${ }^{\text {a }}$ Chemical Activation System-4-(4-nitrobenzyl)pyridine

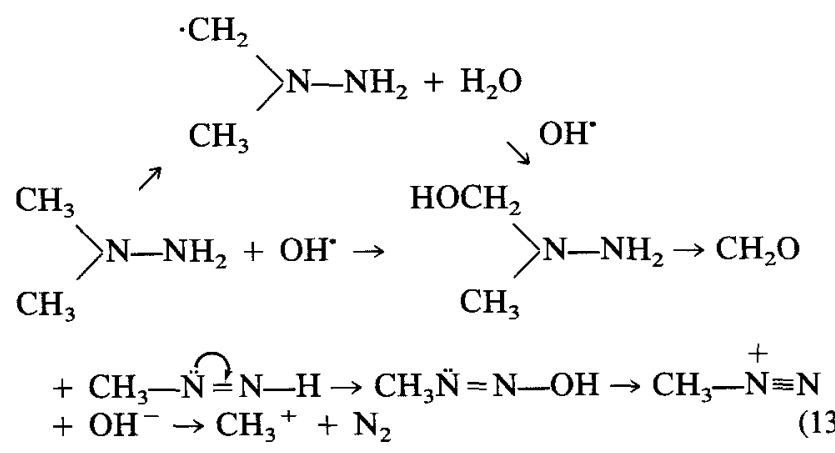

1,2-Dimethylhydrazine dihydrochloride invariably produced an orange color and a gelatinous precipitate in the CAS-NBP assay, thus no reliable results were obtained.

Table 2 lists the positive $(+)$ and negative $(-)$ results obtained with the five test systems discussed.
The important correlations with the compounds tested are: (1) NBP assay with chemical activation and mutagenicity assay with microsomal activation $(r=0.73)$, (2) NBP assay with chemical activation and without microsomal activation ( $r=0.60)$, (3) NBP assay with chemical activation and carcinogenicity tests $(r=0.69)$, (4) NBP assay without chemical activation and mutagenicity without microsomal activation ( $r=0.80)$, and (5) NBP assay without chemical activation and carcinogenicity tests $(r=0.38)$. A fair correlation ( $\mathrm{r}=0.67$ ) was obtained between direct alkylating activity and mutagenicity with microsomal activation. Direct alkylation of NBP, therefore, appears to be a fair indication of direct mutegenicity (Table 3 ).

In summary, the reagent 4(4-nitrobenzyl)pyridine can be considered a model nucleophile and when carefully integrated with the chemical activation system provides a sensitive, quantitative analytical reagent for both direct and induced alkylating agents. Since the test system is purely chemical, testing can be done on compounds and at concentrations that would be toxic or lethal to biological tester oganisms. Further, many biological effects are the consequence of long-term exposure and necessarily require long test periods. Use of the CAS-NBP test in conjunction with other short term tests would greatly reduce the number of false negatives reported.

\section{References}

Aaron CS, Harbach PR, Wiser SK, Grzegorczyk CR, Smith AL (1989) The in vitro unscheduled DNA synthesis (UDS) assay in rat primary hepatocytes: Evaluation of 2-furoic acid and 7 drug candidates. Mutat Res 223:163-169 
Archer MC, Eng VWS (1981) Quantitative determination of carcinogens and mutagens as alkylating agents following chemical activation. Chem Biol Interact 33:207-214

Bardos TJ, Datta-Gupts N, Hebborn P, Triggle DJ (1965) A study of comparative chemical and biological activities of alkylating agents. J Med Chem 8:167-174

Bartsch H, Terracini B, Malaveille C, Tomatis L, Wahrendorf J, Brun G, Dodet B (1983) Quantitative comparison of carcinogenicity, mutagenicity and electrophilicity of 10 direct-acting allkylating agents and of the initial $0^{6}: 7$-alkylguanine ratio in DNA with carcinogenic potency in rodents. Mutat Res 110:181-219

Bruce WR, Heddle JA (1979) The mutagenicity activity of 61 agents as determined by the micronucleus, Salmonella, and sperm abnormality assays. Can J Genetic Toxicol 21:319-334

Chu KC, Milman HA (1981) Review of experimental carcinogenesis by compounds related to vinyl chloride. Environ Health Perspect 41:211-220

Dearfield KL, Abernathy CO, Ottley MS, Brantner JH, Hayes PF (1988) Acrylamide: Its metabolism, developmental and reproductive effects, genotoxicity, and carcinogenicity. Mutat Res 185:45-77

Duverger-van Bogaert M, Lambotte-Vandepaer M, de Meester C: Rollmann B, Poncelet F, Mercier M (1981) Effect of several factors on the liver extract mediated mutagenicity of acrylonitrile and identification of four new in vitro metabolites. Toxicol Lett 7:311-318

Eder E, Neudecker T, Lutz D, Henschler D (1980) Mutagenic potential of allyl and allylic compounds. Structure-activity relationships as determined by alkylating and direct in vitro mutagenic properties. Biochem Pharmacol 29:993-998

Ehrenberg L, Hussain S (1981) Genetic toxicity of some important epoxides. Mutat Res 86:1-113

Farber E (1982) Chemical carcinogenesis, a biological perspective. Am J Pathol 106:271-296

Friedman OM, Boger E (1961) Colorimetric estimation of nitrogen mustards in aqueous media. Anal Chem 33:906-910

Getz ME, Watts RR (1964) Application of 4-(4-Nitrobenzyl)pyridine as a rapid quantitative reagent for organophosphate pesticides. J Offic Agric Chem 47:1094-1096

Habs M, Schmahl D (1981) Inhibition of hepatocarcinogenic activity of diethylnitrosamine (DENA) by ethanol in rats. Hepatogas. troenterol 28:242-244

Hathway DE (1984) Importance of chemical non-enzymic reactions in vivo. In: Molecular aspects of toxicology. London, Royal Society of Chemistry, Chap 10, pp 221-231

Hawks A, Hicks RM, Holsman JW, Magee PN (1974) Morpholog.. ical and biochemical effects of 1,2-dimethylhydrazine and 1methylhydrazine in rats and mice. Br J Cancer 30:429-439

Heddle JA, Hite M, Kirkhart B (1983) The induction of micronuclei as a measure of genotoxicity. Mutat Res 123:61-118

Hemminki K, Falck K, Vainio H (1980) Comparison of alkylation rates and mutagenicity of directly acting industrial and laboratory chemicals. Arch Toxicol 46:277-285

Hemminki K, Hesso A (1984) Reaction products of styrene oxide with guanosine in aqueous media. Carcinogenesis 5(5):601-607

IARC (1982) Monographs on the evaluation of the carcinogenic risk of chemicals to humans. Suppl 4:25-27

Kim JH, Thomas JJ (1991) Use of 4-(nitrobenzyl)pyridine (4-NBP) to test mutagenic potential of slow-reacting epoxides, their corresponding olefins and other alkylating agents. Bull Environ Contam Toxicol., to be published.

McCann J, Choi E, Yamasaki E, Ames BN (1975) Detection of carcinogens as mutagens in the salmonella/microsome test: Assay of 300 chemicals. Proc Nat Acad Sci USA 72:5135-5139

Peto R, Pike MC, Bernstein L, Gold LS, Ames BN (1984) The TD50: A proposed general convention for the numerical description of the carcinogenic potency of chemicals in chronicexposure animals experiments. Environ Health Perspect 58:1-8

Phillipson CE, Ioannides C (1984) A comparative study of the bioactivation of nitrosamines to mutagens by various animal species including man. Carcinogenesis 5:1091-1094

Planche C, Croisy A, Malaveille C, Tomatis L, Bartsch H (1979) Metabolic and mutagenicity studies of DDT and 15 derivatives. Detection of 1,1-bis(p-chlorophenyl)-2,2-dichloroethane and 1,1-bis(p-dichlorophenyl)-2,2,2-trichloroethylacetate (Kelthane ${ }^{\circledR}$ acetate) as mutagens in Salmonella typhimurium and of 1,1-bis(p-chlorophenyl) ethylene oxide, a likely metabolite, as an alkylating agent. Chem Biol Interact 25:157-175

Prival MJ, King VD, Sheldon Jr AT (1979) The mutagenicity of dialkyl nitrosamines in the salmonella plate assay. Environ $\mathrm{Mu}$ tagen 1:95-104

Ragab MTH (1967) 4(4-Nitrobenzyl)pyridine as a spray reagent for organophosphorous pesticides and some of their breakdown products on thin-layer chromatograms. Bull Environ Contam Toxicol 2:279-283

Rannug U, Sundvall A, Ramel C (1978) The mutagenic effect of 1,2-dichloroethane on Salmonella typhimurium. I. Activation through conjugation with glutathion in vitro. Chem Biol Interact 20:1-16

Rannug U, Beije B (1979) The mutagenic effect of 1,2-dichloroethane on Salmonella typhimurium. II. Activation by the isolated perfused rat liver. Chem Biol Interact 24:265-285

Roberts JD, Caserio MC (1964) Basic principles of organic chemistry. W.A. Benjamin, NY

Sawicki E, Bender DF, Hauser TR, Wilson RM, Meeker JE (1963) Five new methods for the spectrophotometric determination of alkylating agents including some extremely sensitive autocatalytic methods. Anal Chem 35:1479-1486

Schuldt PH, Burchfield HP, Stallard DE, Priddle WE, Klein S (1976) Colorimetric determination of micro amounts of dimethyl tetrachloroterphthalate. Contributions from the Boyce Thomson Institute 21:163-173

Soska J, Koukalova B, Ebringer L (1981) Mutagenic activities of simple nitrofuran derivatives. I. Comparison of related compounds in the phase inductest, chloroplast-bleaching and bacterial repair and mutagenicity tests. Mutat Res 81:21-26

Tennant RW, Margolin BH, Shelby MD, Zeiger E, Haseman JK, Spalding J, Caspary W, Resnick M, Stasiewicz S, Anderson B, Minor R (1987) Prediction of chemical carcinogenicity in rodents from in vitro genetic toxicity assays. Science 236:933-941

Voogd CE, van der Stel JJ, Jacobs JJJAA (1981) The mutagenic action of aliphatic epoxides. Mutat Res 89:269-282

von Wright A, Tikkanen L (1980) The comparative mutagenicities of hydrazine and its mono- and di-methyl derivatives in bacterial test systems. Mutat Res 78:17-23

Williams GM (1980) Classification of genotoxic and Eigenetic hepatocarcinogens using liver culture assays. Ann NY Acad Sci 273282

- (1981) Epigenetic mechanisms of action of carcinogenic organochlorine pesticides. ACS Symposium Series No. 160

Yano K, Isobe M (1979) Mutagenicity of $N$-methyl- $N^{\prime}$-aryl- $N$ nitrosourea and $N$-Methyl- $N^{\prime}$-aryl- $N^{\prime}$-methyl- $N$-nitrosoureas in relation to their alkylating activity. Cancer Res 39:5147-5149

Manuscript received September 12, 1991. 